\title{
Review Article \\ Ecological Importance of Insects in Selenium Biogenic Cycling
}

\author{
Nadezhda Golubkina, ${ }^{1}$ Sergey Sheshnitsan, ${ }^{2}$ and Marina Kapitalchuk ${ }^{2}$ \\ ${ }^{1}$ Agrochemical Research Center, All-Russian Scientific Research Institute of Vegetable Breeding and Seeds Production, \\ Russian Academy of Agricultural Sciences, Moscow 143080, Russia \\ ${ }^{2}$ Department of Natural Sciences and Geography, Pridnestrovian State University, 3300 Tiraspol, Moldova
}

Correspondence should be addressed to Nadezhda Golubkina; segolubkina@rambler.ru

Received 23 July 2013; Accepted 30 December 2013; Published 6 February 2014

Academic Editor: Jean-Guy Godin

Copyright (c) 2014 Nadezhda Golubkina et al. This is an open access article distributed under the Creative Commons Attribution License, which permits unrestricted use, distribution, and reproduction in any medium, provided the original work is properly cited.

Selenium is an essential trace element for animal and human beings. Despite the importance of insects in most ecosystems and their significant contribution to the biological cycling of trace elements due to high abundance, population productivity, and diverse ecosystem functions, surprisingly little information is available on selenium bioaccumulation by these arthropods. This review considers selenium essentiality and toxicity to insects as well as insects' contribution to selenium trophic transfer through the food chains. Data on Se accumulation by insects of the Dniester River Valley with no anthropogenic Se loading reveal typically low Se content in necrophagous insects compared to predators and herbivores and seasonal variations in Se accumulation.

\section{Introduction}

Selenium (Se) essentiality in vertebrates has been proven in the second half of the last century, and currently Se is believed to be an essential trace element for all living organisms, except higher plants and yeast $[1,2]$, although initially Se has been mainly considered in terms of its toxicity. However, detailed studies of invertebrates' genome have shown the massive loss of selenoproteins during evolution in some species of nematodes and insects [3].

Insects represent a specific group of animals both in the variety of biological features and in their diverse functions in ecosystems. Certainly, the most particular role in terrestrial zoocoenoses belongs to insects, both in the number of individuals and in their participation in the matter cycling. Only in soil layer they are inferior to other groups of invertebrates in abundance and significance. Furthermore, insects make an appreciable contribution to the biodynamics of freshwater ecosystems [4,5]. Nevertheless, the particular interest to these arthropods in the aspect of their involvement in the biological cycling of trace elements, including Se, has appeared in the last decades.
This brief review considers selenium essentiality and toxicity to insects as well as insects' contribution to selenium trophic transfer through the food chains.

\section{Selenium Essentiality and Toxicity to Insects}

Insects are known to have few selenoproteins [6], and some insects are selenoproteinless (Tribolium castaneum, Bombyx mori, Drosophila willistoni, and Musca domestica) $[3,7,8]$. Se is considered to play an important role in insect physiology. The range of Se concentrations in these arthropods is 0.1$10 \mathrm{mg} \mathrm{kg}^{-1}$ [9], with the upper limit being much higher than that in other groups of animals. Se deficiency is shown to reduce survival and fertility of fruit flies (Drosophila sp., Diptera) [10]. Furthermore, at certain concentrations, Se is beneficial to physiological state and growth of silkworm (Bombyx mori, Lepidoptera) [11]. Moreover, Se supplementation to food of cabbage looper caterpillars (Trichoplusia $n i$, Lepidoptera) makes them more resistant to viral infection [12]. Reared on Se-enriched diet Tenebrio molitor (Coleoptera) is shown to be more protected against low temperatures [13]. It should be noted that even in the houseflies 
TABLE 1: Peculiarities of Se accumulation by plants and effect on insect pollinators in conditions of high Se status [37].

\begin{tabular}{lccc}
\hline Parameter & Hyperaccumulators & Secondary accumulators & Nonaccumulators \\
\hline Biological accumulation level ${ }^{\mathrm{a}}$ & $100-1000$ & $3-10$ & $<1$ \\
$\begin{array}{l}\text { Predominant plant organ of maximum } \\
\text { selenium accumulation }\end{array}$ & Flowers & Leaves & Leaves $^{\mathrm{b}}$ \\
$\begin{array}{l}\text { The main chemical form } \\
\text { Toxicity to insects-pollinators }\end{array}$ & MeSeCys & Se $^{+6}, \mathrm{Se}^{+4}$, SeCys, MeSeCys & Se $^{+6}, \mathrm{Se}^{- \text {proteins }^{\mathrm{b}}}$ \\
\hline
\end{tabular}

${ }^{a}$ corresponds to Se plant/Se soil ratio, ${ }^{b}$ in conditions of Se-fortification.

(Musca domestica, Diptera), for which glutathione peroxidase and its encoding genes have not been found, Se regulates peroxidation regardless of the antioxidant enzymes and glutathione [8].

Se toxicity to insects has been demonstrated at the end of 1930s. It has been noted that the aphids do not inhabit the wheat with a high Se content, and cotton growing on soil supplemented with sodium selenate becomes toxic to bugs and moths [14]. Recent studies have demonstrated that elevated Se concentrations in the diet reduce the survival and vitality of insects and increase duration of the immature developmental stages. At the same time the negative consequences in the food chain occur even in the absence of Se biomagnification. Furthermore, several studies have shown that insect herbivores are not able to detect detrimental Se concentrations in the diet that may have a significant environmental consequence $[15,16]$.

Se is shown to accumulate preferentially in the malpighian tubules and in the midgut of insects. But Se level increases in the rest of the body after saturation point has been reached $[17,18]$. It has been found that insects are able to reduce redundant body burden of toxic elements (including Se) by excretion and various organs participated in the excretory process (exoskeleton at each molting, malpighian tubules, gland secrets, etc.) $[19,20]$.

Different behavioral responses of phytophagous insects to the chemical form of Se in the diet are of particular interest [21]. Inorganic forms of $\mathrm{Se}$ are shown to be antifeedants (particularly selenate, despite the fact that selenite is the most toxic form) compared to organic Se compounds (selenocysteine and selenomethionine). The lack of selenomethionine avoidance may also have substantial environmental implications $[22,23]$. Contrary to phytophagous species detritivorous insects are more tolerant to elevated Se concentrations, and Se toxicity appears at concentrations in the diet far higher than those for phytophages. The most toxic form of Se for detritivores is selenocysteine [24].

The existence of nonaccumulators, secondary accumulators, and hyperaccumulators of Se in natural flora supposes that there should be a certain protective mechanism against Se toxicity for insects-pollinators. Separate data received for Stanleya pinnata (hyperaccumulator) and Brassica juncea (accumulator) indicate that chemical form of the element and its distribution between leaves/flowers may decrease at least partially the undesirable toxic effect of the element (Table 1). While Stanleya pinnata accumulates predominantly nontoxic MetSeCys in flowers, Brassica juncea demonstrates lower concentrations of Se in flowers than in leaves. Nonaccumulator plants though are able to concentrate toxic selenate and Se proteins as a result of fortification with Se are less stable to high Se loading.

\section{Selenium in Terrestrial Food Chains}

Insects play a critical role in ecosystem functioning. They are known to be primary consumers, predators, parasites, and important food sources for many other organisms of higher food webs, and they have the capacity to alter rates and directions of energy and matter fluxes (e.g., as herbivores, pollinators, detritivores, and predators) [5]. Se accumulation levels by insects due to their tremendous biodiversity may vary widely. In general, Se concentrations in predatory insects are much higher than those in nonpredatory species [25].

3.1. Insects' Relationships with Se Accumulator and Hyperaccumulator Plants. It is well known that some plants (Astragalus, Brassica, etc.) are capable to accumulate extraordinary levels of Se (up to $1,000-5,000 \mathrm{mg} \mathrm{kg}^{-1}$ dry weight) [26]. Although many studies have confirmed the hypothesis considering this phenomenon as a way to prevent herbivory [26, 27], some insect species evolutionarily have adapted to toxic concentrations of Se in these plants and eat them harmlessly using specific physiological mechanisms of detoxification [19, 27]. Nevertheless, the protective role of Se in plants against herbivores seems to be more common. Recently it has been suggested that plants absorb high concentrations of metals from the substrate as a self-defense mechanism against infection and herbivores [28]. Several examples of Se accumulation are in good agreement with this hypothesis. Thus, Se hyperaccumulators are known to be stable to herbivory attacks [29]. Selenate treatment of Stanleya pinnata and Brassica juncea increases their resistance to crickets and grasshoppers [30]. Se is shown to protect $B$. juncea (Indian mustard) from cabbage white (Pieris rapae, Lepidoptera) [31]. It is supposed that in such a defense metal ion may kill or inhibit the growth and development of plant pests, cause deterrence, save energydemanding organic defenses, or sometimes confer a rarely complete, pathogen resistance [28]. Caused by herbivory, biotic stress is known to be accompanied by a formation of a large quantity of hydrogen peroxide [32], which decomposition in living organisms is achieved by Se-dependent 
TABLE 2: Selenium content in honey from different regions.

\begin{tabular}{lcc}
\hline Region & Se content in honey, $\mu \mathrm{g} \mathrm{kg}^{-1}$ & References \\
\hline Portugal & $10-29$ & Costa-Silva et al., 2011 [49] \\
Turkey & $38-113$ & Tuzen et al., 2010 [50] \\
Colorado (USA) & $>730$ & Quinn et al., 2011 [37] \\
\hline
\end{tabular}

glutathione peroxidase [1]. The phenomenon of anomalous Se accumulation by leaves of genetically modified potato resistant to Colorado potato beetle (Leptinotarsa decemlineata, Coleoptera) may be considered as an indirect evidence of the protective Se effect against beetle pests [33].

3.2. Selenium in Honey Bees and Its Effects on Pollination. Pollinators strongly influence ecological relationships, ecosystem stability, plant diversity, and evolution. Bees play an important role in pollination. It is estimated that about $1 / 3$ of all plants and plant products eaten by humans are directly or indirectly dependent on bee pollination [34]. Therefore decline of bees' population may have substantial environmental consequences. Recent studies [35-37] have shown that except pesticides and metals [38-40] Se may also be the reason for it. A well-known ecological law of optimum supposes that Se at certain concentrations may promote bee health or may become toxic if ingested in excess.

Se content in bee body depends on Se concentrations in plant nectar and pollen. Thus, Se body burden of bees varies from 1.40 to $15.81 \mathrm{mg} \mathrm{kg}^{-1}$ dry weight [41], while Se concentration in bumblebees may reach the value of $270 \mathrm{mg} \mathrm{kg}^{-1} \mathrm{dry}$ weight, an order of magnitude higher than concentrations toxic to other insects. The predominant chemical form of Se in the last case is nontoxic methylselenocysteine (MeSeCys) [37]. It is worth noting that experiments have shown no preference between high- and low-Se plants for floral visitors [37]. It has a great environmental consequence due to exceeded Se entering the food chain and honey in Se-enriched habitats. Moreover, honey bees are not able to detect more toxic selenate, which causes mortality at lower concentrations than organic forms (selenomethionine). In addition, reduced ability of bees consuming selenate to eat sucrose is observed. Ultimately, effects on survival and foraging behavior may significantly reduce the productivity and longevity of the bee colony and therefore decrement pollination efficiency [35, 36]. Additionally, the results of the above studies suggest that trophic transfer via pollen and nectar to insect pollinators is an important route of Se movements in the food webs.

Furthermore Se transfer with products of beekeeping to human beings may turn out to be significant in regions with high Se status (Table 2). In such regions consumption of about $20 \mathrm{~g}$ of honey may reach $14.6 \%$ from the recommended intake of Se for a healthy human adult (50-70 $\mu \mathrm{g} /$ day). Quinn et al. [37] indicate that honey from plants hyperaccumulators may supply even more Se: about $30-42 \%$ from the recommended Se intake.

\section{Selenium in Freshwater Food Chains}

In freshwater ecosystems amphibiotic insect adults and larvae are important components of fish and bird diets. The studies of lenthic and lothic systems have shown that Se concentrations in aquatic insects are 7 times higher than those of insects inhabiting the streams [42]. At the same time, considering relatively high trophic transfer factors [43] aquatic insect larvae as a significant component of the benthos can be important carriers of trace elements (including Se) from sediment into the water column and to the terrestrial food chains $[4,44,45]$.

Conley et al. [46] have shown that mayflies Centroptilum triangulifer (Ephemeroptera) feeding on periphyton organisms are able to biomagnify Se. The midge larvae (Chironomidae, Diptera) being a significant component of benthic fauna and feeding on detritus microbial biomass are an important link in the detritus food chains accumulating significant concentrations of Se [47]. At the same time, chironomids are characterized by a spatial variability in Se accumulation levels that seems to reflect differences in Se concentrations and bioavailability in sediments [48].

Significantly higher concentrations of Se have been observed in insects inhabiting Se-contaminated wetland Kesterson Reservoir (California, USA) compared to the reference sites, with the concentrations differences being 1-2 orders of magnitude. Most aquatic insects contain higher concentrations of Se than water, sediment, and even algae [25].

\section{Selenium Studies in the Dniester River Valley}

Available published data in the vast majority are laboratory derived studying artificial insect food chains. Few field studies are almost entirely related to the biogeochemical conditions of Se hypergenesis as well as to the areas exposed to anthropogenic Se emissions (due to agricultural drainage, burning of coal, mining of coal, phosphate, sulfide ores, etc.). These studies regard Se as a contaminant that accumulates in high concentrations in the food chain and poses a threat to biota and human beings.

Geochemical conditions of the Dniester River Valley are characterized by high Se bioavailability to plants with no anthropogenic Se loading [51, 52]. Investigation of Se accumulation in natural ecosystems of the territory has revealed wide Se concentration in different insect species ranging from 55 to $1094 \mu \mathrm{g} \mathrm{kg}^{-1}$ wet weight (Figure 1). 


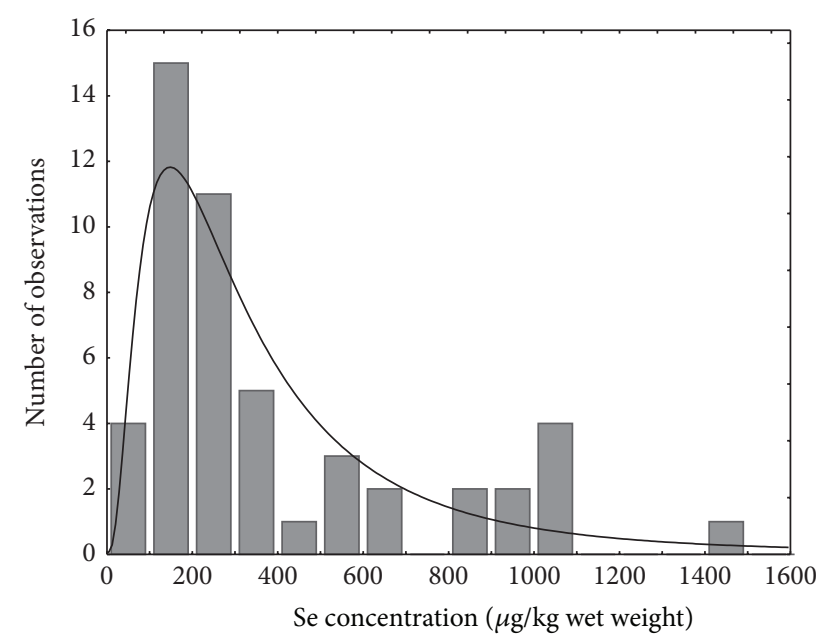

FIGURE 1: Histogram showing log-normal distribution $\left(\chi^{2}=3,647\right.$, $P=0,1614)$ of Se concentration data from 50 samples of insects collected from the Dniester River Valley. Data are individual sample values.

The content of the element in the majority of analyzed samples embraces the range from 100 to $400 \mu \mathrm{g} \mathrm{kg}^{-1}$. The differences in Se concentrations within insect trophic groups shown in Figure 2 demonstrate significantly higher Se concentrations for predatory insects than those for herbivores and necrophages $(H=10,17 ; P=0,0062 ; n=46$; KruskalWallis ANOVA) (the mean Se concentration value for predators is $470 \mu \mathrm{g} \mathrm{kg}^{-1}$ wet weight; $n=28$ ).

Se accumulation levels in herbivorous insect species rarely exceed $250 \mu \mathrm{g} \mathrm{kg}^{-1}$ wet weight (the mean value is $194 \mu \mathrm{g} \mathrm{kg}^{-1}$ wet weight; $n=15$ ) while low Se concentration$127 \mu \mathrm{g} \mathrm{kg}^{-1}$ wet weight $(n=3)$-is typical only in necrophagous insects. Analysis of Se plants-insects transfer factor indicates the phenomenon of Se biomagnification and seasonal variations of Se concentrations in insects. So, Se body burden in two ground beetle species (predators) inhabiting flood plain forests increases from 382 to $1093 \mu \mathrm{g} \mathrm{kg}^{-1}$ in Pterostichus melanarius and from 159 to $500 \mu \mathrm{g} \mathrm{kg}^{-1}$ in Patrobus atrorufus during two months.

\section{Conclusions}

The above review indicates a substantial contribution of insects to the biological cycling of Se in terrestrial and freshwater ecosystems. Insects are shown to possess higher potential to bioaccumulate Se compared to the majority of animal groups. The fact is closely related to insects' position in the food chain since they are a critical link between primary producers and consumers of higher trophic levels. In the case of Se, where the predominant exposure pathway is diet, the reasons for Se accumulation differences of invertebrates (including insects) are central to understanding Se behavior in the food chains [43].

Meanwhile, Se distribution in the food chains of regions with optimal Se content in the environment as well as in the regions with Se deficiency is extremely poorly understood.

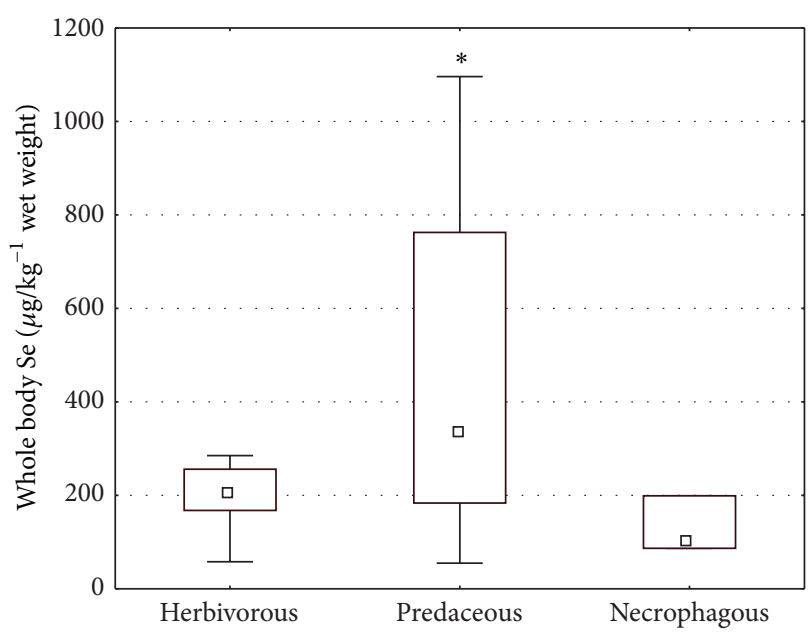

FIGURE 2: Statistical summary of whole body Se concentrations ( $\mu \mathrm{g} \mathrm{kg}^{-1}$ wet weight) for insects with different feeding habits collected from the Dniester River Valley (symbol: median; box: 25th and 75th percentiles; whiskers: minimum and maximum). An asterisk represents a significant difference $(P<0,05)$.

In addition, the studies often do not take into account the importance of other biogeochemical parameters such as biomass, population productivity, and reserves of accumulated elements (mass-transfer) allowing to assess insect contribution to Se biogenic cycling.

\section{Conflict of Interests}

The authors declare that there is no conflict of interests regarding the publication of this paper.

\section{References}

[1] N. Golubkina and T. Papazyan, Selenium in Nutrition. Plants, Animals, Human Beings, Pechatny Gorod, Moscow, Russia, 2006.

[2] G. R. Hogan and H. G. Razniak, "Selenium-induced mortality and tissue distribution studies in Tenebrio molitor (Coleoptera: Tenebrionidae)," Environmental Entomology, vol. 20, no. 3, pp. 790-794, 1991.

[3] C. E. Chapple and R. Guigó, "Relaxation of selective constraints causes independent selenoprotein extinction in insect genomes," PLoS ONE, vol. 3, no. 8, Article ID e2968, 2008.

[4] V. B. Chernishov, Insect Ecology, Moscow, Russia, 1996.

[5] T. D. Schowalter, Insect Ecology: An Ecosystem Approach, Academic Press, San Diego, Calif, USA, 3rd edition, 2011.

[6] Y. Zhang and V. N. Gladyshev, "General trends in trace element utilization revealed by comparative genomic analyses of $\mathrm{Co}, \mathrm{Cu}$, $\mathrm{Mo}, \mathrm{Ni}$, and Se," The Journal of Biological Chemistry, vol. 285, no. 5, pp. 3393-3405, 2010.

[7] A. V. Lobanov, D. L. Hatfield, and V. N. Gladyshev, "Selenoproteinless animals: selenophosphate synthetase SPS1 functions in a pathway unrelated to selenocysteine biosynthesis," Protein Science, vol. 17, no. 1, pp. 176-182, 2008.

[8] T. W. Simmons, I. S. Jamall, and R. A. Lockshin, "Selenium modulates peroxidation in the absence of glutathione peroxidase in 
Musca domestica," Biochemical and Biophysical Research Communications, vol. 165, no. 1, pp. 158-163, 1989.

[9] A. D. Pokarzhevsky, Geochemical Ecology of Terrestrial and Soil Animals (Bioindicative and Radiological Aspects), Moscow, Russia, 1993.

[10] F. J. Martin-Romero, G. V. Kryukov, A. V. Lobanov et al., "Selenium metabolism in Drosophila. Selenoproteins, selenoprotein mRNA expression, fertility, and mortality," The Journal of Biological Chemistry, vol. 276, no. 32, pp. 29798-29804, 2001.

[11] S. Smitha and A. V. B. Rao, "Effects of selenium on the physiology of heart beat, oxygen consumption and growth in silkworm Bombyx mori L.," American-Eurasian Journal of Toxicological Sciences, vol. 2, no. 4, pp. 215-219, 2010.

[12] H. J. R. Popham, K. S. Shelby, and T. W. Popham, "Effect of dietary selenium supplementation on resistance to baculovirus infection," Biological Control, vol. 32, no. 3, pp. 419-426, 2005.

[13] A. Audas, G. R. Hogan, and H. Razniak, "Incubation temperature as a modifying factor on survival of Tenebrio molitor reared in selenium-containing media," Journal of Toxicology and Environmental Health, vol. 44, no. 1, pp. 115-122, 1995.

[14] A. L. Moxon, "Selenium: its occurrence in the rocks and soils, absorption by plants, toxic action in animals, and possible essential role in animal nutrition," in Trace Elements, Proceedings of the Conference, C. A. Lamb, O. G. Bentley, and J. M. Beattie, Eds., pp. 175-191, Academic Press, New York, NY, USA, 1958.

[15] D. B. Vickerman and J. T. Trumble, "Biotransfer of selenium: effects on an insect predator, Podisus maculiventris," Ecotoxicology, vol. 12, no. 6, pp. 497-504, 2003.

[16] D. B. Vickerman, J. K. Young, and J. T. Trumble, "Effect of selenium-treated alfalfa on development, survival, feeding, and oviposition preferences of Spodoptera exigua (Lepidoptera: Noctuidae)," Environmental Entomology, vol. 31, no. 6, pp. $953-$ 959, 2002.

[17] W. E. Hillwalker, P. C. Jepson, and K. A. Anderson, "Selenium accumulation patterns in lotic and lentic aquatic systems," Science of the Total Environment, vol. 366, no. 1, pp. 367-379, 2006.

[18] K. Lalitha, P. Rani, and V. Narayanaswami, "Metabolic relevance of selenium in the insect Corcyra cephalonica: uptake of 75Se and subcellular distribution," Biological Trace Element Research, vol. 41, no. 3, pp. 217-233, 1994.

[19] R. Andrahennadi, Biotransformation of selenium and arsenic in insects: environmental implications [Ph.D. dissertation], University of Saskatchewan, 2009.

[20] D. B. Vickerman, J. T. Trumble, G. N. George, I. J. Pickering, and H. Nichol, "Selenium biotransformations in an insect ecosystem: effects of insects on phytoremediation," Environmental Science and Technology, vol. 38, no. 13, pp. 3581-3586, 2004.

[21] C. L. Mogren and J. T. Trumble, "The impacts of metals and metalloids on insect behavior," Entomologia Experimentalis et Applicata, vol. 135, no. 1, pp. 1-17, 2010.

[22] J. T. Trumble, G. S. Kund, and K. K. White, "Influence of form and quantity of selenium on the development and survival of an insect herbivore," Environmental Pollution, vol. 101, no. 2, pp. 175-182, 1998.

[23] D. B. Vickerman and J. T. Trumble, "Feeding preferences of Spodoptera exigua in response to form and concentration of selenium," Archives of Insect Biochemistry and Physiology, vol. 42, no. 1, pp. 64-73, 1999.
[24] P. D. Jensen, M. D. Rivas, and J. T. Trumble, "Developmental responses of a terrestrial insect detritivore, Megaselia scalaris (Loew) to four selenium species," Ecotoxicology, vol. 14, no. 3, pp. 313-322, 2005.

[25] H. M. Ohlendorf, "Ecotoxicology of selenium," in Handbook of Ecotoxicology, pp. 465-500, CRC Press, Boca Raton, Fla, USA, 2nd edition, 2003.

[26] M. L. Galeas, E. M. Klamper, L. E. Bennett et al., "Selenium hyperaccumulation reduces plant arthropod loads in the field," New Phytologist, vol. 177, no. 3, pp. 715-724, 2008.

[27] J. L. Freeman, C. F. Quinn, M. A. Marcus, S. Fakra, and E. A. H. Pilon-Smits, "Selenium-tolerant Diamondback Moth disarms hyperaccumulator plant defense," Current Biology, vol. 16, no. 22, pp. 2181-2192, 2006.

[28] Ch. Poschenrieder, R. Tolrà, and J. Barceló, "Can metals defend plants against biotic stress?” Trends in Plant Science, vol. 11, no. 6, pp. 288-295, 2006.

[29] M. Hartl and I. T. Baldwin, "Evolution: the ecological reverberations of toxic trace elements," Current Biology, vol. 16, no. 22, pp. R958-R960, 2006.

[30] J. L. Freeman, S. D. Lindblom, C. F. Quinn, S. Fakra, M. A. Marcus, and E. A. H. Pilon-Smits, "Selenium accumulation protects plants from herbivory by Orthoptera via toxicity and deterrence," New Phytologist, vol. 175, no. 3, pp. 490-500, 2007.

[31] B. Hanson, G. F. Garifullina, S. D. Lindblom et al., "Selenium accumulation protects Brassica juncea from invertebrate herbivory and fungal infection," New Phytologist, vol. 159, no. 2, pp. 461-469, 2003.

[32] I. Ślesak, H. Ślesak, M. Libik, and Z. Miszalski, “Antioxidant response system in the short-term post-wounding effect in Mesembryanthemum crystallinum leaves," Journal of Plant Physiology, vol. 165, no. 2, pp. 127-137, 2008.

[33] N. Golubkina and K. Skriabin, "Anomalous accumulation of selenium by genetically modified potato, stable to Colorado beetle," Journal of Food Composition and Analysis, vol. 23, no. 2, pp. 190-193, 2010.

[34] N. Bradbear, Bees and Their Role in Forest Livelihoods: A Guide to the Services Provided by Bees and the Sustainable Harvesting, Processing and Marketing of Their Products, Food and Agriculture Organization of the United Nations, Rome, Italy, 2009.

[35] K. R. Hladun, O. Kaftanoglu, D. R. Parker et al., "Effects of selenium on development, survival, and accumulation in the honeybee (Apis mellifera L.)," Environmental Toxicology and Chemistry, vol. 32, no. 11, pp. 2584-2592, 2013.

[36] K. R. Hladun, B. H. Smith, J. A. Mustard, R. R. Morton, and J. T. Trumble, "Selenium toxicity to honey bee (Apis mellifera 1.) pollinators: effects on behaviors and survival," PLOS ONE, vol. 7, no. 4, Article ID e34137, 2012.

[37] C. F. Quinn, C. N. Prins, J. L. Freeman et al., "Selenium accumulation in flowers and its effects on pollination," New Phytologist, vol. 192, no. 3, pp. 727-737, 2011.

[38] G. Balayiannis and P. Balayiannis, "Bee honey as an environmental bioindicator of pesticides' occurrence in six agricultural areas of Greece," Archives of Environmental Contamination and Toxicology, vol. 55, no. 3, pp. 462-470, 2008.

[39] G. Celli and B. Maccagnani, "Honey bees as bioindicators of environmental pollution," Bulletin of Insectology, vol. 56, no. 1, pp. 137-139, 2003.

[40] N. Desneux, A. Decourtye, and J.-M. Delpuech, "The sublethal effects of pesticides on beneficial arthropods," Annual Review of Entomology, vol. 52, pp. 81-106, 2007. 
[41] A. Roman, "Levels of copper, selenium, lead, and cadmium in forager bees," Polish Journal of Environmental Studies, vol. 19, no. 3, pp. 663-669, 2010.

[42] J. Hesketh, "Nutrigenomics and selenium: gene expression patterns, physiological targets, and genetics," Annual Review of Nutrition, vol. 28, pp. 157-177, 2008.

[43] Ecological Assessment of Selenium in the Aquatic Environment, CRC Press, Boca Raton, Fla, USA, 2010.

[44] S. J. Hamilton, "Review of selenium toxicity in the aquatic food chain," Science of the Total Environment, vol. 326, no. 1-3, pp. 131, 2004.

[45] Th. S. Presser and S. N. Luoma, "A methodology for ecosystemscale modeling of selenium," Integrated Environmental Assessment and Management, vol. 6, no. 4, pp. 685-710, 2010.

[46] J. M. Conley, D. H. Funk, and D. B. Buchwalter, "Selenium bioaccumulation and maternal transfer in the mayfly Centroptilum triangulifer in a life-cycle, periphyton-biofilm trophic assay," Environmental Science and Technology, vol. 43, no. 20, pp. 7952-7957, 2009.

[47] J. Alaimo, R. S. Ogle, and A. W. Knight, "Selenium uptake by larval Chironomus decorus from a Ruppia maritima-based benthic/detrital substrate," Archives of Environmental Contamination and Toxicology, vol. 27, no. 4, pp. 441-448, 1994.

[48] J. C. Malloy, M. L. Meade, and E. W. Olsen, "Small-scale spatial variation of selenium concentrations in chironomid larvae," Bulletin of Environmental Contamination and Toxicology, vol. 62, no. 2, pp. 122-129, 1999.

[49] F. Costa-Silva, M. Maia, C. C. Matos, E. Calçada, A. I. R. N. A. Barros, and F. M. Nunes, "Selenium content of Portuguese unifloral honeys," Journal of Food Composition and Analysis, vol. 24, no. 3, pp. 351-355, 2011.

[50] M. Tuzen, S. Silici, D. Mendil, and M. Soylak, "Trace element levels in honeys from different regions of Turkey," Food Chemistry, vol. 103, no. 2, pp. 325-330, 2007.

[51] N. A. Golubkina, S. S. Sheshnitsan, M. V. Kapitalchuk, and N. V. Pedurari, "Particularities of selenium bioaccumulation by insects in forest-steppe and steppe of the Dniester Valley," in Geoecological and Bioecological Issues of the Northern Black Sea Region, Proceedings of the Conference, pp. 82-83, Tiraspol, Moldova, 2012.

[52] M. V. Kapitalchuk, I. P. Kapitalchuk, and N. A. Golubkina, "Selenium accumulation and migration in components of the biogeochemical food chain "soil-plant-human" in Moldova," Volga Journal of Ecology, no. 3, pp. 323-335, 2011 (Russian). 

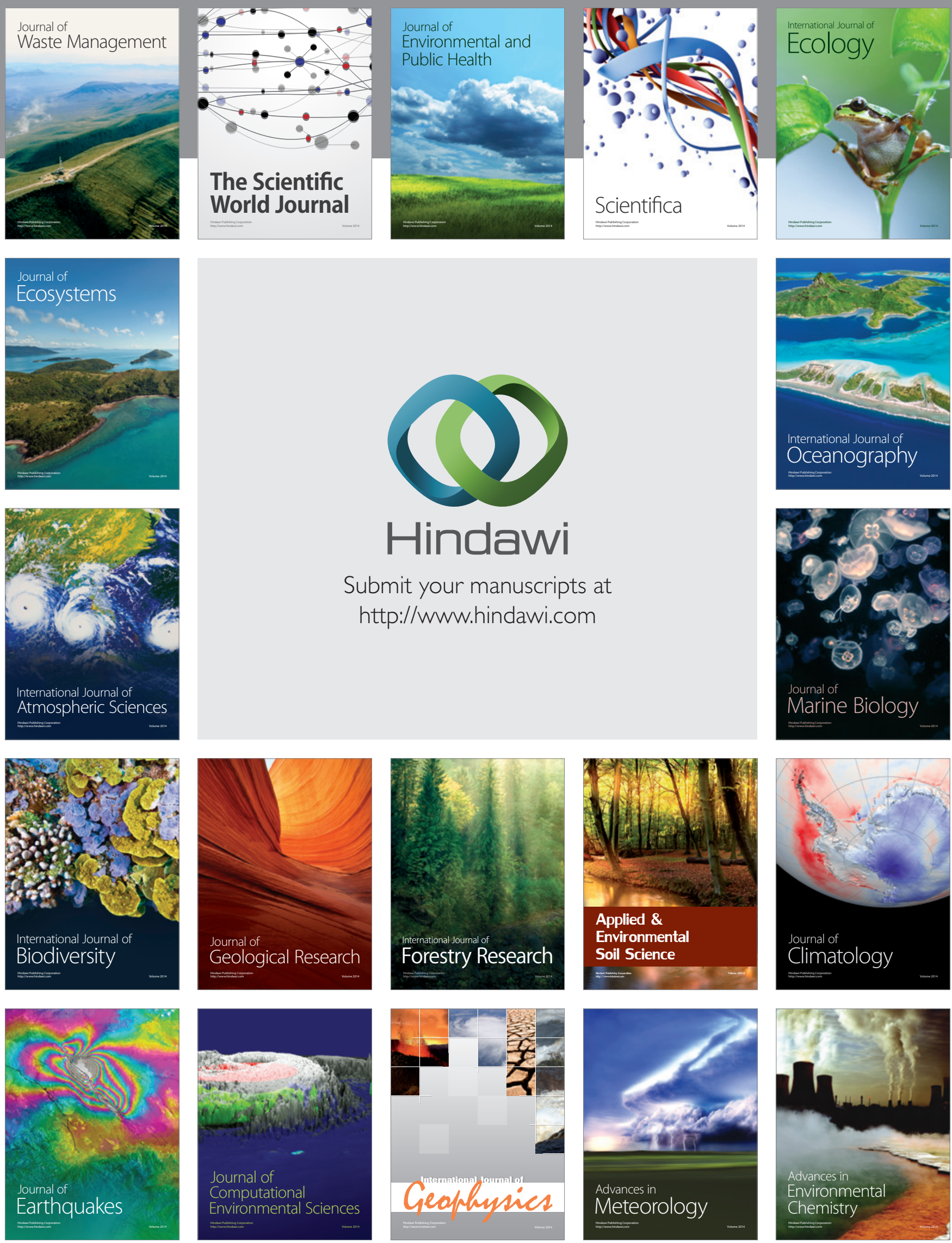